\title{
Advance directives, proxy opinions, and treatment restrictions in patients with severe stroke
}

Floor A. S. de Kort ${ }^{1 \dagger}$, Marjolein Geurts ${ }^{1{ }^{*}}$, Paul L. M. de Kort ${ }^{2}$, Julia H. van Tuijl ${ }^{2}$, Ghislaine J. M. W. van Thiel ${ }^{3}$, L. Jaap Kappelle ${ }^{1}$ and H. Bart van der Worp ${ }^{1}$

\begin{abstract}
Background: Patients with severe stroke often do not have the capacity to participate in discussions on treatment restrictions because of a reduced level of consciousness, aphasia, or another cognitive disorder. We assessed the role of advance directives and proxy opinions in the decision-making process of incapacitated patients.

Methods: Sixty patients with severe functional dependence (Barthel Index $\leq 6$ ) at day four after ischemic stroke or intracerebral hemorrhage were included in a prospective two-center cohort study. The decision-making process with respect to treatment restrictions was assessed by means of a semi-structured questionnaire administered to the treating physician at the day of inclusion.

Results: Forty-nine patients (82\%) did not have the capacity to participate in the decision-making process. In eight patients, there was no discussion on treatment restrictions and full care was installed. In 41 patients, the decision whether to install treatment restrictions was discussed with proxies. One patient had a written advance directive. In the remaining 40 patients, proxies based their opinion on previously expressed wishes of the patient (18 patients) or advised in the best interest of the patient (22 patients). In 36 of 41 patients, treatment restrictions were installed after agreement between physician and proxy. At six months, 23 of 49 patients had survived. In only three of them the decision on treatment restrictions was based on previously expressed wishes. Remarkably, two of these survivors could not recall any of their alleged previously expressed wishes.
\end{abstract}

Conclusions: Treatment restrictions were installed in the majority of incapacitated patients after stroke. Proxy opinions frequently served as the best way to respect the patients' autonomy, but their accuracy remains unclear.

Keywords: Stroke, Ethics, End-of-life decisions, Advance care planning, Advance directives, Proxy opinions, Surrogate decision making

\section{Background}

Patients with severe stroke have a high risk of long-term disability or death. A substantial proportion of in-hospital deaths after severe stroke occur in the context of withholding or withdrawal of life prolonging treatments [1,2]. The decision to forgo life prolonging treatment usually evolves from discussions that are complicated by several factors. First, in contrast to more chronic diseases, stroke

\footnotetext{
*Correspondence: m.geurts-2@umcutrecht.nl

${ }^{\dagger}$ Equal contributors

'Department of Neurology and Neurosurgery, Brain Center Rudolf Magnus,

University Medical Center Utrecht, Utrecht, the Netherlands

Full list of author information is available at the end of the article
}

occurs almost always unexpectedly. Secondly, prognosis is often uncertain in the early stage. Thirdly, continuation of treatment may allow patients to survive for months or years, at the cost of being left in a state of disability that might be against their wishes [3]. Fourthly, patients with severe stroke often do not have the capacity to participate in the decision-making process on treatment restrictions themselves because of a reduced level of consciousness, aphasia, or another cognitive disorder [3]. In these cases, proxy opinions and advance directives are used to warrant patients' autonomy [4].

The principle of autonomy is considered one of the fundamental principles of bioethics in Western societies 
and it plays a major role in modern health care systems [5]. Respect for the autonomy of the patient implies that the patient has the capacity to decide intentionally, with understanding, and without controlling influences that would mitigate against a free and voluntary decision [5]. A direct translation of respect for patients' autonomy is the doctrine of informed consent. For most treatments, explicit informed consent is required and a capacitated patient has the right to refuse treatment. In The Netherlands, among other countries such as Belgium, Denmark and Canada, the requirement of informed consent is embedded in the law [6]. In incapacitated patients, a proxy decision maker has to be identified. This legal representative of the patient has to consent to treatment on his behalf. Dutch law states that the patient can be represented by several proxies in descending order: an appointed guardian; an individual to whom the patient has given a durable power of attorney that includes the authority to make health care decisions; the patient's spouse or registered domestic partner; children of the patient who are at least eighteen years of age, parents of the patient or adult brothers and sisters of the patient [6]. Advance directives can help to respect the patient's (former) autonomy. A written non treatment directive has a strong legal status in the Netherlands: in principle, it equals the current refusal of a capacitated patient [6]. The law does not distinguish between self-created advance directives or specific documents for healthcare decisionmaking. Advance directives are not nationally registered in the Netherlands and are usually kept by the patient and/or by his general practitioner.

Although discussions about treatment restrictions are routine in the care for patients with severe stroke in many countries, it is unclear how physicians implement advance directives and proxy opinions in these discussions. In this study, we assessed current practices in the decision whether or not to install treatment restrictions in incapacitated patients with severe stroke.

\section{Methods}

We selected patients from the 'Advance Directives And Proxy opinions in acute sTroke' (ADAPT) cohort [7], a prospective two-center cohort study which included consecutive patients admitted at the stroke unit with acute severe ischemic stroke or intracerebral hemorrhage and a very small chance of functional independency after 6 months, defined as Barthel Index (BI) $\leq 6$ out of 20 at day 4 [8]. Patients with subarachnoid hemorrhage and patients without an available legal representative were excluded from the study. Patients were included between September 2012 and December 2013 in the University Medical Center Utrecht, and between January and December 2013 in the St. Elisabeth hospital in Tilburg, a large regional teaching hospital in The Netherlands. The main aim of the ADAPT study was to assess the association between the placement of treatment restrictions and mortality in patients who had survived the first four days after severe ischemic stroke or intracerebral hemorrhage. The original cohort study included 60 patients [7].

For this secondary study, all patients whom their treating physicians considered incapacitated to participate in discussions on treatment restrictions were selected (49 patients). The judgment of the patient's decision-making capacity was based on a clinical assessment using the internationally accepted definition of capacity: understanding, expressing a choice, appreciation, and reasoning [9].

The legal representative appointed conformed with Dutch law as described in the Introduction. The study was approved by the institutional review board of each center and written informed consent was obtained from each patient or a legal representative.

\section{Data collection}

Demographic and stroke characteristics were collected from the patients' charts. The decision-making process concerning the instalment of treatment restrictions was assessed by a semi-structured questionnaire administered to the treating physician at the day of the patient's inclusion. The questionnaire included both open-ended and closed-ended questions on the following items:

1. Physician's judgment of the decision-making capacity of the patient whether or not to install treatment restrictions.

2. The presence and content of advance directives. Identification of advance directives was left to the responsibility of the treating physician.

3. The role of proxies in the decision-making process, as perceived by the treating physician.

4. Factors that contributed to the instalment of treatment restrictions.

\section{Follow-up}

One investigator (FASdK) visited each patient who had survived and their caregiver at six months $(+/-$ six weeks) after stroke. Their reflection on the decisionmaking process, including the presence of advance directives, was assessed by a semi-structured questionnaire (Additional file 1). All questionnaires were analyzed by hand; coding verbatim was not used.

\section{Results}

Of 60 patients included in ADAPT [7], 49 (82\%) patients were, according to their physician, incapacitated to decide whether or not to install treatment restrictions. The reasons for incapacity were a reduced level of consciousness in 14 (29\%), aphasia in 10 (20\%), cognitive impairment in $6(12 \%)$, or a combination of two or more 
of these conditions in 19 (39\%) cases. Twenty-one treating physicians filled out the questionnaires.

The median time between stroke onset and inclusion was 6 days (range, 4-10). The mean age of the patients was 72 years (SD 15); 26 (53\%) were male; 27 (55\%) had an ischemic stroke; the median National Institutes of Health Stroke Scale (NIHSS) score on admission was 18 (range, 12-21), and the median BI at day 4 was 0 (range, $0-2$ ).

\section{Treatment restrictions}

In 36 of 49 incapacitated patients (74\%), treatment restrictions had been installed at the time of study inclusion (Fig. 1). The remaining 13 patients received full care. Reasons for the decision whether or not to install treatment restrictions are summarized in Table 1 . Table 2 shows the type of treatment restrictions installed.

\section{Discussions on treatment restrictions}

In 8 of 49 (16\%) incapacitated patients, a discussion on treatment restrictions had not taken place, the treating physician had decided on full care in these cases (Fig. 1). Reasons not to discuss treatment restrictions were a young age (88\%) and the physician's expectation of a good functional recovery $(88 \%)$ (Table 1 ). In the remaining 41 patients, treatment restrictions were discussed. Nineteen of 41 patients had previously expressed their wishes (one patient had a written advance directive and 18 of them had orally expressed their wishes) (Fig. 1, Table 2).

\section{Advance directives and proxy opinions}

In 41 of 49 incapacitated patients (82\%), the decision on treatment restrictions was discussed with the patients' proxies. One patient had a written advance directive requesting restrictive care in case of dependency, a "do not resuscitate-order" was installed. In the remaining 40 patients, the decision whether or not to install treatment restrictions was informed by proxy opinions. Proxy opinions were either based on previously expressed wishes of the patient (18 patients, resulting in restrictive care in 17 (94\%) cases), or based on the perceived best interest of the patient in the absence of such previous expressions (22 patients, resulting in restrictive care in 18 patients $(82 \%)$ and full care in four (18\%) (Fig. 1).

\section{Follow up}

At six months, 23 (47\%) patients who were incapacitated at the time of the discussion on treatment restrictions had survived. Fifteen of them (65\%) had a poor functional outcome.

Six of eight patients in whom no discussion on treatment restrictions had taken place survived. All six patients

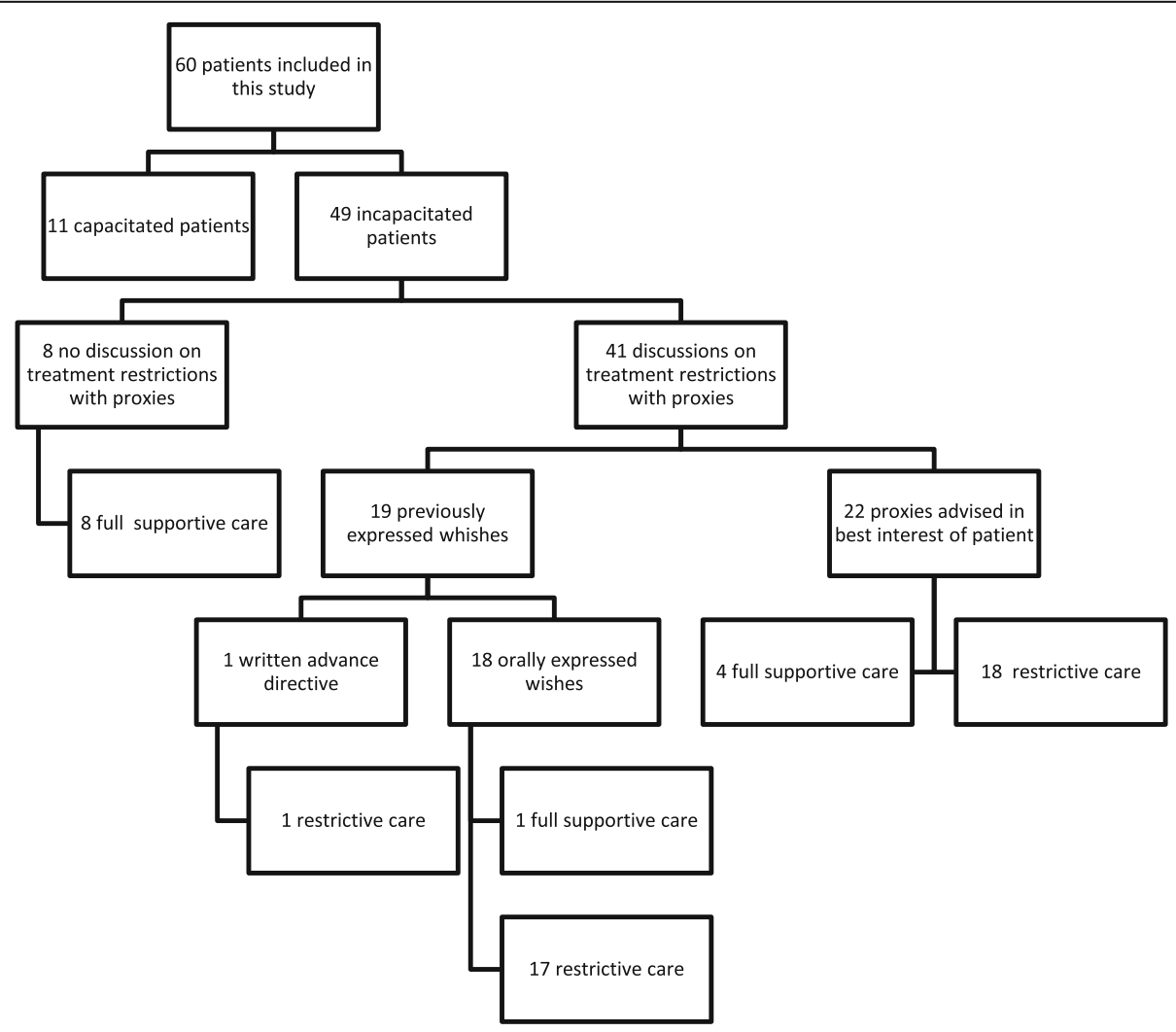

Fig. 1 Flow of patients through this study 
Table 1 Physicians' reasons for restrictive or full care (more than one option possible)

\begin{tabular}{|c|c|c|c|}
\hline & \multirow{2}{*}{$\begin{array}{l}\text { Incapacitated patients with } \\
\text { restrictive care }(n=36)\end{array}$} & \multicolumn{2}{|c|}{ Incapacitated patients with full care $(n=13)$} \\
\hline & & $\begin{array}{l}\text { Patients without discussions on } \\
\text { treatment restrictions }(n=8)\end{array}$ & $\begin{array}{l}\text { Patients with discussions on } \\
\text { treatment restrictions }(n=5)\end{array}$ \\
\hline Proxy and/or patient preferences, $\mathrm{n}(\%)$ & $14(39)$ & NA & $3(60)$ \\
\hline Physicians' estimate of functional recovery, n(\%) & $32(89)$ & $7(88)$ & $3(60)$ \\
\hline Age, $n(\%)$ & $24(67)$ & $7(88)$ & $1(20)$ \\
\hline Comorbidity, n(\%) & $18(50)$ & $0(0)$ & $2(40)$ \\
\hline Discomfort, $n(\%)$ & $5(14)$ & $0(0)$ & $0(0)$ \\
\hline Religion, n(\%) & $0(0)$ & $0(0)$ & $1(20)$ \\
\hline
\end{tabular}

had received full care after stroke. At six months, five of them retrospectively agreed with this decision.

The single patient with a written advance directive was one of the survivors at six months. This patient still agreed on the content of his advance directive (restrictive care in case of dependency). At follow-up, none of the patients stated they had a written advance directive that was missed in the acute stage.

Only three of 18 patients for whom treatment decisions were discussed with proxies and were based on previously expressed wishes, survived up to six months. Remarkably, two of these survivors could not recall any of their alleged previously expressed wishes.

Of the 22 patients for whom proxies had advised in their best interest without known previously expressed wishes, 13 (59\%) survived up to six months. Four of them could not complete the interview at six months, three because of aphasia and one patient was moribund at the time of follow-up. The remaining nine survivors retrospectively agreed with the decisions on treatment restrictions made in the early phase of their stroke. One of nine patients stated he orally expressed wishes about treatment to proxies before the stroke; this expression was not reported by the treating physician.

\section{Discussion}

This study shows that in incapacitated patients with a very recent stroke, discussions on treatment restrictions are complex. Advance directives are scarce. Patients' autonomy is mostly respected via proxies, who base their opinion on previously expressed wishes of the patient or advised in the best interest of the patient. This mostly resulted in restrictive care. It remained unclear whether proxies adequately reflected the patients' preferences. In a substantial proportion (16\%) of incapacitated patients, no discussion on treatment restrictions between treating physicians and patients or their proxies had taken place.

In our study, an advance directive was available in only one out of 49 patients. This is most likely the consequence of the acute course of the disease, in combination with a low prevalence of advance directives in the general population [10]. Population studies in The Netherlands show that only $7 \%$ of the general population has completed an advance directive [11]. The prevalence of advance directives in advanced stages of cancer has been estimated about 55\% [12,13]. Most advance directives are written in the last days of life, which suggests that disease itself is an important reason to write an advance directive [14]. The value of advance directives can be limited [3] as they often relate to very specific situations such as coma, and applying these wishes to a situation in which the patient has a focal deficit caused by stroke might not be appropriate $[15,16]$. In a German observational cohort study, less than half of the available advance directives were considered applicable in patients suffering severe acute stroke [17].

In case of incapacity of the patient to participate in the decision-making process, the treating physician should discuss the condition of the patient with a legal representative, usually a family member. In many countries, legal representatives have a strong legal status [18]. In

Table 2 Decisions on treatment restrictions in incapacitated patients

\begin{tabular}{|c|c|c|c|}
\hline & \multirow{2}{*}{$\begin{array}{l}\text { Patients without discussions on } \\
\text { treatment restrictions }(n=8)\end{array}$} & \multicolumn{2}{|c|}{ Patients with discussions on treatment restrictions $(n=41)$} \\
\hline & & $\begin{array}{l}\text { Patients who previously expressed } \\
\text { their wishes (written/oral) }(n=19)\end{array}$ & $\begin{array}{l}\text { Patients in whom was advised in } \\
\text { their best interest }(n=22)\end{array}$ \\
\hline Full supportive care & 8 & 1 & 4 \\
\hline DNR & 0 & 4 & 6 \\
\hline Withhold admission at ICU & 0 & 6 & 9 \\
\hline No curative treatment of complications & 0 & 1 & 0 \\
\hline Withhold artificial nutrition and hydration & 0 & 7 & 3 \\
\hline
\end{tabular}

DNR Do not resuscitate, ICU Intensive Care Unit 
clinical practice, advance directives and proxy opinions are equally effective in influencing doctors' decisions [19]. Vignette studies show that physicians have a mild preference to forgo life sustaining treatment in case of contradictions between written advance directives and proxy opinion [20]. In our study, two of the three patients in whom a proxy opinion was based on alleged previously expressed wishes, and who could be interviewed at six months, could not recall this expression. Although the number is very small, it raises questions about the accuracy of proxy opinions. These findings are in line with the accuracy of surrogate decisions observed in hypothetical scenario studies [21]. Legal representatives may be affected by their own stress and by distraction from familial or social factors and recall bias [3].

Two factors further complicate the use of advance directives and proxy opinions in acute stroke patients. First, the 'disability paradox': the fact that patients often report greater happiness and quality of life than healthy people predict they would under the same circumstances [22]. Second, the 'response shift': a change of internal standards, values and the conceptualization of quality of life as a result of changes in health status [23]. A considerable proportion of patients after severe stroke recaptures a good quality of life despite severe disability [24]. It is hard to identify patients in the acute stage after stroke who might adapt well to their new situation [22, 25, 26].

In current practice, implementing patient centeredness of care in acute severe stroke is challenging. Efforts should be made to improve individualized end-of-life decision-making. The prevalence of advance directives in the general population can be increased by advance care planning campaigns on the community level, such as the 'Speak Up'-campaign in Canada [27] and the 'Advance Care Planning Australia'-initiative [28]. In these campaigns, special attention should be drawn to stroke scenarios to improve the applicability of advance directives in severe stroke. However, in the light of the phenomena of response shift and the disability paradox, the predictive value of treatment directives in stroke in general should not be overestimated. A joint assessment of the physician and the proxy with regard to the patient's best interest at the moment of actual decision-making on life sustaining treatments should always be put into the equation.

As treatment restrictions are independently associated with mortality [7], decisions on withholding or withdrawal of life-sustaining treatments should be taken with great caution. The treating physician carries the final responsibility for medical treatment decisions in incapacitated patients. It can be an enormous emotional burden for legal representatives to feel the sole responsibility for treatment restrictions and it is therefore essential to avoid giving families the impression they are being asked to make these major decisions on their own [29-31].
To implement patient preferences in the decision-making process, we previously introduced a 5-step approach [3]. The first step is collection of evidence, in which the treating physician defines clinical problems and outweighs the risks and benefits of withdrawal or continuation of specific medical treatments. Second, the physician shares information with legal representatives, in which he/she explains the clinical problems and expected prognosis, and sketches scenarios in which specific medical treatment is withdrawn or given. A crucial part of this step is that legal representatives share patient preferences and values with the physician. Third, the physician critically appraises the collected information and addresses biases of both prognostication and patient preferences that could influence outcome. Fourth, the physician makes a recommendation and promotes shared-decision making. Finally, the physician provides adequate follow-up.

\section{Limitations}

This study has limitations. The sample size prohibits strong generalization of our findings. We included patients who were severely dependent but still alive at day four, because treatment restrictions are most often considered in these patients [15]. Therefore, our results cannot be extrapolated to situations at different points in time after stroke or in patients who are less severely disabled at day four, and we may have missed discussions and decisions on treatment restrictions at later stages. The data are relatively old (inclusion started in September 2012), but there is no reason to assume that this affects our findings. Furthermore, information on the decision-making process was obtained from the treating physician and therefore reflects the physician's vision on patient preferences. However, this appears appropriate because it is the physician who finally makes the decision to withhold or continue specific treatments. At six-months follow-up, recall bias might have played a role, which may have led to more positive reflection on the process, and patients might have given desirable answers on questions about treatment limitations during home-visits. Finally, we did not contact proxies of deceased patients.

\section{Conclusions}

Our study shows that advance directives are scarce in patients with a major disabling stroke who cannot participate in the discussion whether or not treatment restrictions should be installed. Proxy opinions are frequently used as a way to respect the patients' autonomy, but the treating physician should be cautious not to overestimate the capability of these proxies to reflect the opinion of the patient as based on previously expressed wishes. 


\section{Additional file}

Additional file 1: Questionnaire patient 6 months after stroke. (PDF 407 kb)

\section{Abbreviations}

ADAPT: Advance Directives And Proxy opinions in acute sTroke; BI: Barthel Index; NIHSS: National Institutes of Health Stroke Scale

\section{Acknowledgements}

None.

\section{Funding}

M. Geurts and H.B. van der Worp are supported by the Dutch Heart Foundation (2010B239 and 2010 T075, respectively).

\section{Availability of data and materials}

The datasets during and/or analyzed during the current study are available from the corresponding author on reasonable request.

\section{Authors' contributions}

FASK helped to refine the study idea, contributed to the data collection, performed the data analysis, interpreted the data, and prepared the first draft of the manuscript. MG contributed to the study design, data collection and analyses, helped interpreting the data, and contributed to writing. JHT helped with data collection and contributed to writing. GJMWT, PLMK and LK helped to refine the study idea, helped interpreting the data and contributed to writing. HBW conceived the study, helped to refine the study idea, helped interpreting the data and contributed to writing. All authors read and approved the final manuscript.

\section{Ethics approval and consent to participate}

The study was approved by the institutional review board of each center and written informed consent was obtained from each patient or a legal representative.

\section{Consent for publication}

Not applicable.

\section{Competing interests}

The authors declare that they have no competing interests.

\section{Publisher's Note}

Springer Nature remains neutral with regard to jurisdictional claims in published maps and institutional affiliations.

\section{Author details}

${ }^{1}$ Department of Neurology and Neurosurgery, Brain Center Rudolf Magnus, University Medical Center Utrecht, Utrecht, the Netherlands. ${ }^{2}$ Department of Neurology, Elisabeth-Twee Steden ziekenhuis, Tilburg, the Netherlands. ${ }^{3}$ Julius Center for Health Sciences and Primary Care, University Medical Center Utrecht, Utrecht, the Netherlands.

Received: 1 May 2017 Accepted: 9 November 2017 Published online: 14 November 2017

\section{References}

1. Kelly AG, Hoskins KD, Holloway RG. Early stroke mortality, patient preferences, and the withdrawal of care bias. Neurology. 2012;79:941-4.

2. Becker KJ, Baxter AB, Cohen WA, Bybee HM, Tirschwell DL, Newell DW, et al. Withdrawal of support in intracerebral hemorrhage may lead to self-fulfilling prophecies. Neurology. 2001;56:766-72.

3. Geurts M, Macleod MR, van Thiel GJ, van Gijn J, Kappelle LJ, van der Worp $H B$. End-of-life decisions in patients with severe acute brain injury. Lancet Neurol. 2014;13:515-24.

4. Stiggelbout AM, Van der Weijden T, De Wit MP, Frosch D, Legare F, Montori VM, et al. Shared decision making: really putting patients at the centre of healthcare. BMJ. 2012;344:e256

5. Beauchamp TL, Childress JF. Principles of biomedical ethics. New York: Oxford University Press; 2013. Chapter 4

6. Vezzoni $\mathrm{C}$. The legal status and social practice of treatment directives in the Netherlands. PhD thesis. University of Groningen; 2005.
7. Geurts M, de Kort FAS, de Kort PLM, van Tuijl JH, van Thiel GJMW, Kappelle $\omega$, et al. Treatment restrictions in patients with severe stroke are associated with an increased risk of death. Eur Stroke J. 2017; https://doi.org/10.1177/ 2396987317704546

8. Kwakkel G, Veerbeek JM, Harmeling-van der Wel BC, van Wegen E, Kollen BJ, Early Prediction of functional Outcome after Stroke (EPOS) Investigators. Diagnostic accuracy of the Barthel Index for measuring activities of daily living outcome after ischemic hemispheric stroke: does early poststroke timing of assessment matter? Stroke. 2011:42:342-6.

9. Grisso T, Appelbaum PS. Abilities related to competence. In: Assessing competence to consent to treatment. A guide for physicians and other health professionals. New York: Oxford University Press; 1998. p. 31.

10. van Wijmen MP, Rurup ML, Pasman HR, Kaspers PJ, Onwuteaka-Philipsen BD. Advance directives in the Netherlands: an empirical contribution to the exploration of a cross-cultural perspective on advance directives. Bioethics. 2010;24:118-26.

11. Raijmakers NJ, Rietjens JA, Kouwenhoven PS, Vezzoni C, van Thiel GJ, van Delden JJ, et al. Involvement of the Dutch general population in advance care planning: a cross-sectional survey. J Palliat Med. 2013;16:1055-61.

12. McDonald JC, du Manoir JM, Kevork N, Le LW, Zimmermann C. Advance directives in patients with advanced cancer receiving active treatment: attitudes, prevalence, and barriers. Support Care Cancer. 2017;25:523-31.

13. Patel Ml, Bhattacharya J, Asch SM, Kahn J. Acceptance of advance directives and palliative care referral for veterans with advanced cancer: a retrospective analysis. Am J Hosp Palliat Care. 2016:33:742-7.

14. Levin T, Li Y, Weiner JS, Lewis F, Bartell A, Piercy J, et al. How do-notresuscitate orders are utilized in cancer patients: timing relative to death and communication-training implications. Palliat Support Care. 2008;6:341-8.

15. Alonso A, Ebert AD, Dorr D, Buchheidt D, Hennerici MG, Szabo K. End-of-life decisions in acute stroke patients: an observational cohort study. BMC Palliat Care. 2016;15:38.

16. Suarez II. Are advance directives useful in acute stroke? Crit Care Med. 2013;41:1581-2

17. Alonso A, Dörr D, Szabo K. Critical appraisal of advance directives given by patients with fatal acute stroke: an observational cohort study. BMC Med Ethics. 2017:18:7.

18. Silveira MJ, Kim SY, Langa KM. Advance directives and outcomes of surrogate decision making before death. N Engl J Med. 2010;362:1211-8.

19. Escher M, Perneger TV, Rudaz S, Dayer P, Perrier A. Impact of advance directives and a health care proxy on doctors' decisions: a randomized trial. J Pain Symptom Manag. 2014;47:1-11.

20. Escher M, Perrier A, Rudaz S, Dayer P, Perneger TV. Doctors' decisions when faced with contradictory patient advance directives and health care proxy opinion: a randomized vignette-based study. J Pain Symptom Manag. 2015;49:637-45.

21. Shalowitz DI, Garrett-Mayer E, Wendler D. The accuracy of surrogate decision makers: a systematic review. Arch Intern Med. 2006;166:493-7.

22. Ubel PA, Loewenstein G, Schwarz N, Smith D. Misimagining the unimaginable: the disability paradox and health care decision making Health Psychol. 2005;24:S57-62

23. Sprangers MA, Schwartz CE. Integrating response shift into health-related quality of life research: a theoretical model. Soc Sci Med. 1999:48:1507-15.

24. Geurts M, van der Worp HB, Kappelle $\sqcup$, Amelink GJ, Algra A, Hofmeijer J, et al. Surgical decompression for space-occupying cerebral infarction: outcomes at 3 years in the randomized HAMLET trial. Stroke. 2013;44:2506-8.

25. Bruno MA, Bernheim JL, Ledoux D, Pellas F, Demertzi A, Laureys S. A survey on self-assessed well-being in a cohort of chronic locked-in syndrome patients: happy majority, miserable minority. BMJ Open. 2011;1:0.

26. Patel MD, Tilling K, Lawrence E, Rudd AG, Wolfe CD, McKevitt C. Relationships between long-term stroke disability, handicap and health-related quality of life. Age Ageing. 2006;35:273-9.

27. National Advance Care Planning Task Group. Speak Up. 2017. http://www. advancecareplanning.ca. Accessed 2 Jul 2017.

28. ACPA. Advance care planning Australia. 2017. http://www. advancecareplanning.org.au. Accessed 2 Jul 2017.

29. de Boer ME, Depla M, Wojtkowiak J, Visser MC, Widdershoven GA, Francke $A L$, et al. Life-and-death decision-making in the acute phase after a severe stroke: interviews with relatives. Palliat Med. 2015:29:451-7.

30. Wendler D, Rid A. Systematic review: the effect on surrogates of making treatment decisions for others. Ann Intern Med. 2011;154:336-46.

31. Cowey E, Smith LN, Stott DJ, McAlpine CH, Mead GE, Barber M, et al. Impact of a clinical pathway on end-of-life care following stroke: a mixed methods study. Palliat Med. 2015;29:249-59. 